\title{
Communication features of the hybrid learning
}

\author{
Liliya R. Tukhvatulina \\ Department of Management \\ National Research Tomsk Polytechnic University \\ Tomsk, Russia \\ lilytuhv@yandex.ru
}

\author{
Alexandra V. Eremina \\ Department of Management \\ National Research Tomsk Polytechnic University \\ Tomsk, Russia \\ science_world@mail.ru
}

\author{
Natalia V. Cherepanova \\ Department of Management \\ National Research Tomsk Polytechnic University \\ Tomsk, Russia \\ asor81@yandex.ru
}

\begin{abstract}
The experience of using a hybrid course, developed for higher education undergraduates being analyzed in the given article. Particular attention is paid to the communication features of the hybrid course. Also the change of sender's and recipient's roles in the electronic environment is described, as well as the transformation of the educational message format. The feedback and the importance of context of the communication process in the hybrid course are determined. The merits and disadvantages of hybrid courses are evaluated. Considering characteristics of the particular communication process in electronic learning environment and the analysis of the advantages and disadvantages of hybrid courses, potential areas of development of hybrid courses are identified.
\end{abstract}

Keywords - hybrid learning; e-learning, communication; forms of communication.

\section{INTRODUCTION}

The statement that modern society is the society of information does not bring any doubts. Information technologies enter all spheres of our lives and change the communication system. Even education system, being the most conservative sphere of society, is undergoing major changes due to the impact of new communication technologies. Important to note that this informational impact is changing its role from passive to active actor that forms a new learning technology - E-learning. In contemporary education date, e-learning is represented in several forms: 1) Web-support of a courses, provided in the traditional format, where lectures and seminars are held in the usual manner, however students' independent work is performed in an electronic environment; 2) distance learning - in this particular case, the entire educational activity takes place in an electronic environment, and last but not least, 3) hybrid or blended learning is represented by a combination of traditional classes with the transfer of the lectures or seminars in the electronic environment. Hence the experience of using the latest forms of e-learning will be discussed in this article.
The aim of the article is to identify and analyze features of communication interaction of the participants in hybrid learning, to recognize the advantages and disadvantages of this new format of training in higher education system.

The theoretical background of our research can be found in research of forms and features of the communicative process, including investigations of Lasswell, Shannon, Klyagin, Korogodin, Leach, Lotman, Mironov, Pocheptsov, Sokolov. Features of electronic communications are featured on the basis of works of Bell, Rozin, Alexeyev. Pedagogical features of e-learning are revealed in the works of Veledinsky, Dorofeeva, Prokhorets, Igonina, Sclater, Golyshev.

The empirical background of the given study is found in the experience of the implementation of real university course, which is built on a hybrid model of e-learning for undergraduates business students. The results of students' surveys, conducted before and after completing the course, are also used for the analysis.

\section{THE TYPES OF COMMUNICATION IN HYBRID COURSES}

The idea of the necessity of development and implementation of a hybrid courses in the educational process of higher educational institutions is widely spread and brings to life the lively discussion. Pioneers of e-learning share their experiences; discuss various aspects of this form of learning. At the forefront come urgent questions of technical, economic, social, cultural change in high education. In this article we will particularly focus on the communication features of the hybrid learning, due to the fact that communication is the basic process for the formation of students' knowledge.

Communication in a hybrid course has the key features that need to be taken into consideration in the development and usage of such new types of courses.

We believe that the first feature of the new hybrid course is presence of several levels of communication. As a baseline we consider the electronic form of communication itself. In other words, the traditional format of educational communication is 
transferred to the electronic environment, which undoubtedly implies significant changes associated with all elements of the communication process. The next level or rather the addstructure can be seen in what we consider the target communication or education-oriented communication. Without any doubt, it imposes specific requirements on the educational organization that implements the communication process.

The second feature is that the hybrid course implies a combination of several kinds of communication. So we can name new communication types based on participant actors involved in the e-learning:

- Interpersonal communication - direct interaction of the teacher with the student.

- Group communication - interaction between students themselves.

Based on the interaction format, hybrid course implies:

- Traditional educational communication - synchronous learning when teachers and students are at the same time in the same place like in the classroom.

- Synchronous communication using information technology - synchronous training differs from the previous one in the form of teacher-student interaction. Teacher and students might have different locations, i.e., the geographical location. In other words, the educational interaction occurs at one time, but in different places for participants. For example, online webinar, or synchronous communication on the course forum.

- Asynchronous communication - is the type of communication with a time interval between sending and receiving the messages. In other words, teacher and students interact at different times and also in different locations. Examples such type of educational communication could be self-study work or group work of students during the semester.

\section{THE FEATURES OF COMMUNICATION IN HYBRID COURSES}

Communication in the framework of a hybrid course is diverse. Each of the mentioned above types contain the possibility for distortion or deformation of the communication process. To rationalize the types and kind diversity of communication processes and to demonstrate the advantages and disadvantages within the hybrid learning model we will use the communication process, which includes: the sender, the message, the recipient, feedback and context in which communication takes place (Fig 1).

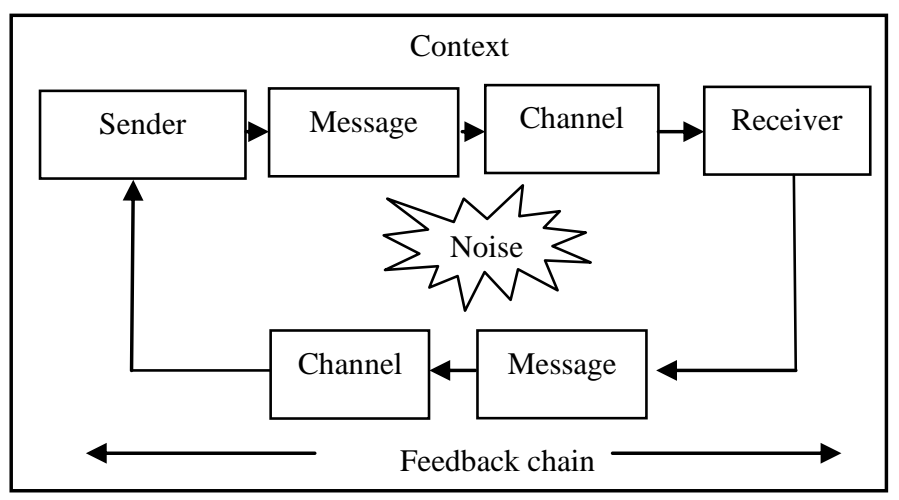

Fig. 1 General communication model.
Each element of the communication process brings its own specific features and has both positive and negative effects on the efficiency of communication process in education. This is the effect we will investigate further.

Sender is the element of the communication process that generates, encrypts and sends the information in the educational process. And traditionally it was a teacher's role.

It is the teacher, while creating the course, who chooses and prepares relevant information for students, than places it in a certain way on the electronic educational platform. And from his point, the teacher's activity is not so much different from what teacher used to do in the traditional form of learning.

The specifics of the role of the sender as part of a hybrid learning is the teacher ceases to be the sole sender in the education process. Implementation of the services "Forum", "Glossary" and "Wiki edits" in the LMS Moodle, involves student participation as a sender. It is a unique situation for education. For example, within the Wiki, students have an opportunity to create and edit personal course assignments; they may develop group projects, etc. As part of a hybrid course it is also possible for students to carry out a mutual review and to evaluate the work of fellow students. Thus, there is a new orientation of the role of the student from passive recipient to active sender. It should be pointed out that the role transformation is positively evaluated by students (Fig. 2 and Fig. 3).

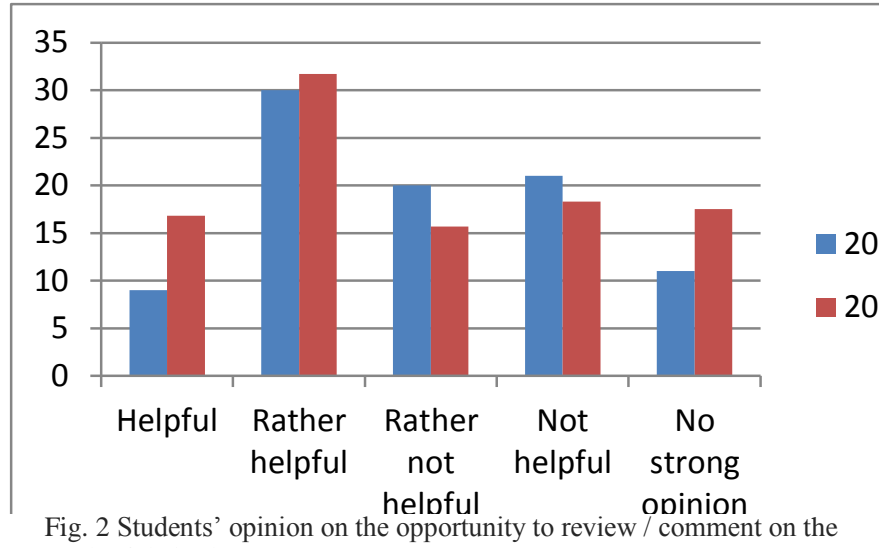
work of their classmates [1].

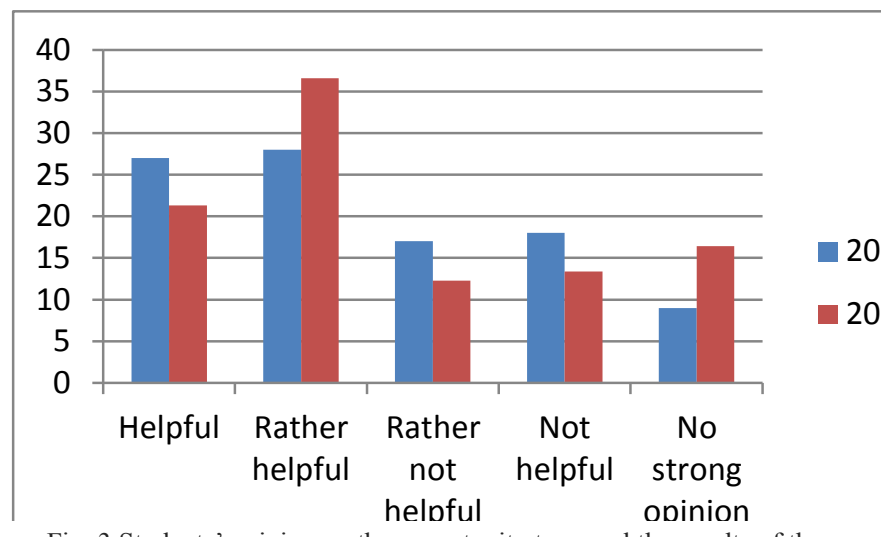

Fig. 3 Students' opinion on the opportunity to reveal the results of the completed assignments for discussion/ update [1]. 
So according to the conducted survey among business students enrolled to the hybrid course [1], 57, 9 per cent versus 25,7 per cent of respondents appreciated the opportunity to reveal the results of completed assignments for general discussion and update with fellow students; 48,5 per cent versus 34 per cent rated positively the opportunity to review and comment on the work of their classmates.

The most radical changes, compared with the traditional educational communication, occurred with the message itself. Message is the communication element is now moved to the electronic environment and developed specific and widely discussed features [2].

It should be pointed out that a common feature of electronic messages is their semiotic. It reveals, for example, in a "developed system of signs expressing emotions emoji's, Internet names - nicknames, names of e-mail and mailboxes, and electronic addresses of websites that, in general terms, represented in a set of certain figures" [3]. It is necessary highlight that educational electronic space is also not free from these signs, figures, and symbols. In addition, the usage of signs and symbols leads to de-formalization of the message, making even "teacher - student" communication less formal. Speaking about the specifics of the message in hybrid educational courses, we can specify the following:

- A variety of messages. Electronic environment, for example, LMS Moodle offers a wide range of possible activities. Even such a traditional element of education as lecture, in the electronic environment can be provided in the form of webinars, online mini-lectures (synchronous form of communication) or video lectures (asynchronous form of communication). Group tasks could be implemented in the form of forums, seminars, assignments, surveys, etc. Various forms of communication in a hybrid course make learning subjects more attractive to today's students, who, according to many researchers, inherent fragmented thinking. This type of thinking is characterized by short, vivid messages: "If the world is a text, the stalemate world is filled with quotations from the text" [4]. Thus, the modern educational space must be meaningful in terms of the information provided, and also must have attractive form to be understandable and attractive for students.

- Clarity of messages. An important feature of communication in electronic educational environment is accuracy. In the process of development and operation of hybrid courses clarity and unambiguous understanding of instructions, evaluation criterions, procedures, and deadlines of assignment have a great importance. It must be noted that in terms of the traditional forms of the educational process, the message in the hybrid courses should have excess accuracy.

- The flexibility of the message. The content of the hybrid course is easily changeable. The teacher has the opportunity to adjust the content of the education material to the level of theoretical knowledge and perception of the particular student group; change the number of theoretical and practical material up to date; or add the results of current research on the relevant subject. Information technologies allow build-in different educational paths of the discipline. LMS Moodle system allows you to hide and reveal certain elements of the course. Thus, compared to the traditional form of the knowledge transference which is basically built on lectures, on the educational publication materials or printed media, such as books and teaching aids, electronic educational resources are capable of dynamic development.

- Determination of the content of message. This feature is somewhat opposing the previous one. By the determination of the messages we understand lack of the self-search activity in students. Electronic educational LMS Moodle platform besides placing necessary theoretical material and variety of tasks is compulsorily filled with additional materials such as links to the video materials, other power point presentations, articles, textbooks, and etc. In this situation, the student is deprived of choice and, very importantly, the selection of relevant sources of information.

The next element of the communication process - the recipient is also being transformed in the framework of electronic communications. One aspect of this transformation has already been specified in this article in the discussion of the sender, when student starts to perform some functions of the sender, forming the course content. In addition, in the electronic educational system takes place de-personification of the recipient. In other words, the teacher has no certainty that the assignments are completed a particular student. Depersonification is the feature of any communication process in an electronic environment, however, in the field of education it can lead to the loss of value of the educational process, create difficulties of adequate assessment of students' knowledge. The problem has a partial solution within the framework of the synchronous part of the course.

Feedback is an essential element of the communication process of any kind. Organization of a hybrid model of education implies that the feedback is expressed in various forms. The most important features are unbrokenness and rapidness of feedback. Electronic communication requires a response within a day. Thus, the teacher has to be accessible constantly, i.e. respond to questions, assignments, discussion of students, or the feedback ceases to perform the function of motivation.

Context is an element of communication that has also undergone significant changes. Effective communication process exists in both physical and semantic context. In the hybrid form of education the physical education context disappears. There are no educational institution building, lecture rooms, time frames of the educational units (classes), etc. Students may perform tasks at any place and at any time they wish such as at home, at park etc. On the one hand, this free format of assignments allows the student to build their own convenient schedule of learning process. On the other hand, the loss of the disciplinary aspect may undesirably affect the part of the student audience, which is experiencing difficulties in self-organization. 


\section{CONCLUSION}

To sum up the selected features of hybrid learning, we can frame the advantages and disadvantages of this new form of the educational process. The advantages of hybrid courses that we have noticed after its implementation are the following:

- Familiarity of modern forms of communication for contemporary students. It includes semiotic, brevity, clarity of a message.

- A variety of tasks.

- Wide range of self-study work of students.

- Possibility for development and rapid updating of educational messages.

- The promptness feedback.

- Opportunity for students to build up their own convenient schedule for work on the assignments.

Along with distinguished advantages we can indicate some drawbacks, such as:

- Lack of the context of educational messages.

- Determination (certainty) of educational content.

- Loss of the personification of the recipient (the student).

- Increase of work amount for the teacher in terms of constant monitoring of the course content sent by the students (due to the fact that students, along with the teacher, become equal senders of educational messages), to provide feedback and update the content of the course.

- Technical difficulties and support in creating and operating an electronic course.

In conclusion it is necessary to indicate that the introduction of hybrid courses in the learning practice of higher education institutions is an important innovation of modern education. Indeed, this form of the educational process has many advantages, some of which we have indicated in this article.

However, when developing hybrid course all the limitations and drawbacks of this form of learning must be taken into account. For efficient organization of hybrid courses in the universities it is necessary to solve a number of tasks different from communication practices, for example, development of special ethical policies for the digital environment [5], as well as sustainable habits of usage different e-learning opportunities both for student.

\section{REFERENCES}

[1] Survey of TPU full-time students on the usage of e-learning in the educational process. Informational and analytical note on the results of sociological research. - Tomsk, 2015. $-12 \mathrm{p}$.

[2] Effect of the Internet on the consciousness and the structure of knowledge: Sat. Art. Moscow, 2004. - 239 p.

[3] L.R. Tukhvatulin, "Influence of the specifics of the communication act in the Internet for educational sphere," Modernization of professional post-graduate education, Tomsk, p. 168, November 2005 [Mater. Intern. Scient. Conf.].

[4] F.I. Girenok, Metaphysics of stalemate (Tongues of a tired man): monograph. Moscow: Maze, 1995.

[5] N.V. Cherepanova, "The ethical foundation of the Russian management," Management in Russia and abroad, vol. 6, pp. 3-11, 2010.

[6] E.K. Prokhorets, "Didactics and methodical analysis of the training programs on the Internet for learning a foreign language," The educational standards of new generation. Organizational and technological and logistical support, Tomsk, pp. 114-115, 2001 [ Mater. Proc. Scient. Conf.]

[7] S.B. Veledinskaya and M.Y. Dorofeeva, "Blended Learning: Secrets of efficiency,"Higher education today, vol. 8, pp. 8-13, 2014. 